Review

\title{
Hair ethyl glucuronide levels as a marker for alcohol use and abuse: A review of the current state of the art
}

\author{
Cleo L. Crunelle ${ }^{\mathrm{a}, \mathrm{b}, *}$, Michel Yegles ${ }^{\mathrm{c}}$, Alexander L.N. van Nuijs ${ }^{\mathrm{a}}$, Adrian Covaci ${ }^{\mathrm{a}}$, \\ Mireille De Doncker ${ }^{\mathrm{d}}$, Kristof E. Maudens ${ }^{\mathrm{a}}$, Bernard Sabbe ${ }^{\mathrm{b}, \mathrm{e}}$, Geert Dom ${ }^{\mathrm{b}, \mathrm{f}}$, \\ Willy E. Lambert ${ }^{\mathrm{g}}$, Peter Michielsen ${ }^{\mathrm{h}}$, Hugo Neels ${ }^{\mathrm{a}, \mathrm{d}}$ \\ a Toxicological Centre, University of Antwerp, Universiteitsplein 1, B2610 Antwerp, Belgium \\ b Collaborative Antwerp Psychiatric Research Institute (CAPRI), University of Antwerp, Universiteitsplein 1, B2610 Antwerp, Belgium \\ ${ }^{\mathrm{c}}$ Laboratoire National de Santé - Toxicologie, Université du Luxembourg, 162a, av. Faiencerie, L1511, Luxembourg \\ d Toxicology Laboratory, ZNA Stuivenberg, Lange Beeldekenstraat 267, B2060 Antwerp, Belgium \\ e Psychiatric Hospital Sint-Norbertus, Stationstraat 22, B2570 Duffel, Belgium \\ ${ }^{f}$ Psychiatric Centre Alexian Brothers, Provinciesteenweg 408, B2530 Boechout, Belgium \\ ${ }^{g}$ Laboratory of Toxicology, Ghent University, Harelbekestraat 72, B9000 Gent, Belgium \\ ${ }^{\mathrm{h}}$ Department of Gastroenterology and Hepatology, University Hospital Antwerp, Wilrijkstraat 10, B2650 Antwerp, Belgium
}

\section{A R T I C L E I N F O}

\section{Article history:}

Received 27 May 2013

Received in revised form 7 October 2013

Accepted 13 October 2013

Available online 30 October 2013

\section{Keywords:}

Ethyl glucuronide

Alcohol

Hair

Gas chromatography

Liquid chromatography

Mass spectrometry

\begin{abstract}
A B S T R A C T
Background: Ethyl glucuronide (EtG) is a minor alcohol metabolite that has been proposed as a stable marker in hair to detect and quantify alcohol consumption over long time periods.

Methods: We provide an outline of currently available techniques for EtG hair sample analysis and highlight the pitfalls related to data interpretation. The literature of EtG analysis has been reviewed from January 1980 up to August 2013. In addition, we present an overview of the clinical and forensic studies which have used EtG quantification in hair as a marker for alcohol consumption/abstinence and we provide suggestions for future research.

Results: EtG is a stable marker in hair that can be used to detect and quantify alcohol consumption over long time periods. This alcohol metabolite remains in hair after complete elimination of alcohol. Currently, there are three main analytical techniques used to quantify EtG in hair: gas chromatography-mass spectrometry (GC-MS), gas chromatography-tandem mass spectrometry (GC-MS/MS), and liquid chromatography-tandem mass spectrometry (LC-MS/MS). No standardized protocols are yet available for the analysis of EtG levels in hair samples, and the current protocols vary in sample preparation and extraction procedures. Variables such as hair length, cosmetic treatment, gender, and pathophysiological conditions influence the final results and should be taken into account.

Conclusions: EtG quantification in hair is a useful tool for the objective detection of alcohol consumption over extended time periods, but care should be taken when interpreting the results.
\end{abstract}

(C) 2013 Elsevier Ireland Ltd. All rights reserved.

\section{Contents}

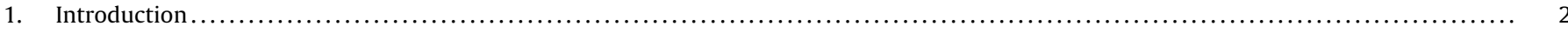

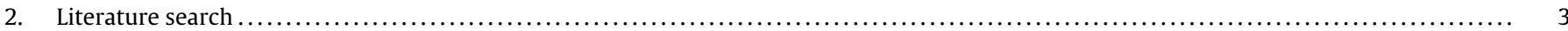

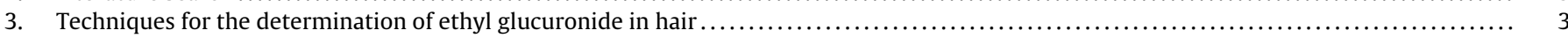

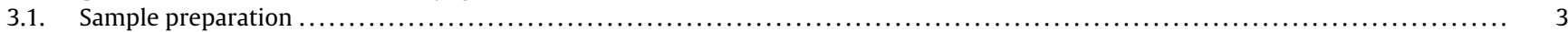

3.2. Gas chromatography-mass spectrometry (GC-MS) and gas chromatography-tandem mass spectrometry (GC-MS/MS)............. 5

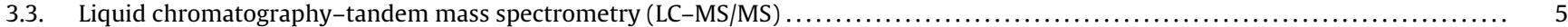

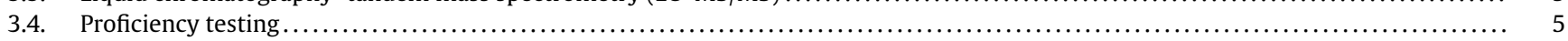

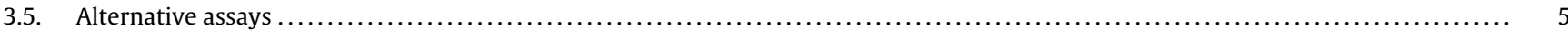

\footnotetext{
* Corresponding author at: Toxicological Centre - University of Antwerp, Campus Drie Eiken, Universiteitsplein 1-R.3.27, 2610 Antwerp (Wilrijk), Belgium. Tel.: +32032652767.

E-mail address: cleo.crunelle@gmail.com (C.L. Crunelle).
} 


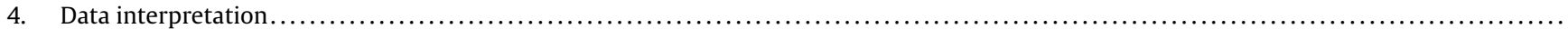

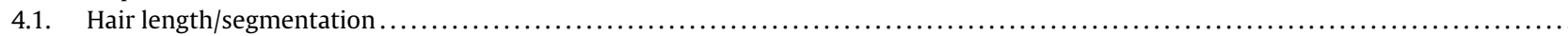

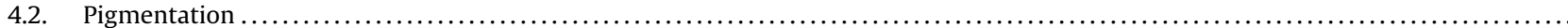

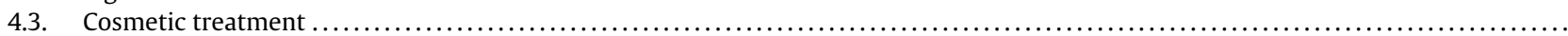

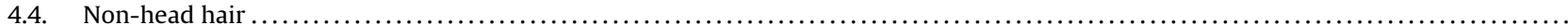

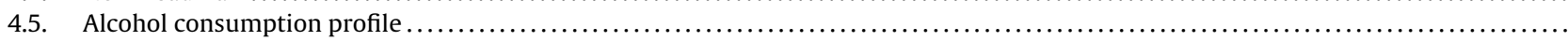

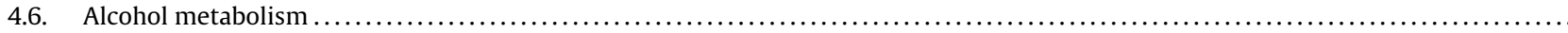

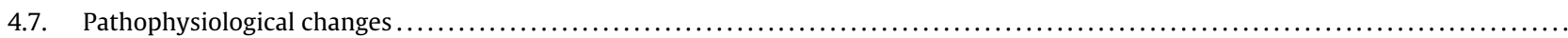

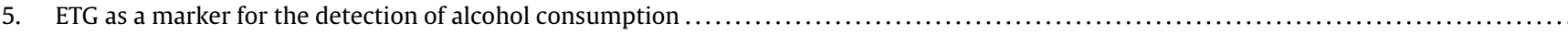

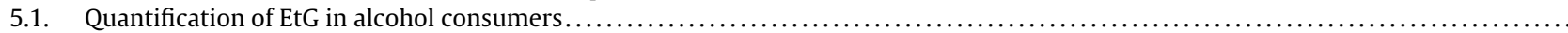

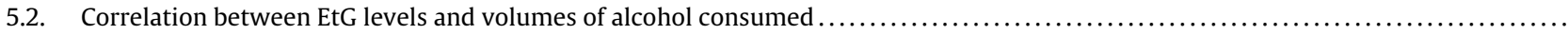

6. Summary and conclusions....

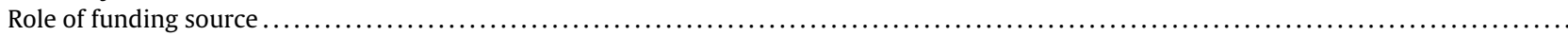

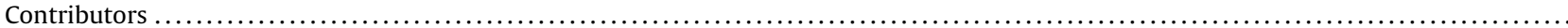

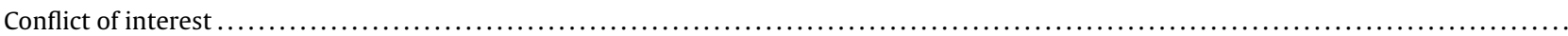

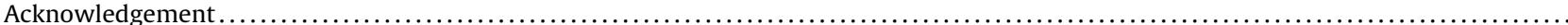

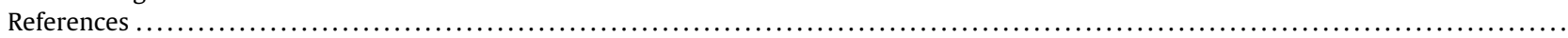

\section{Introduction}

The detection and quantification of alcohol consumption is of significance in both forensic and clinical settings and can have a large impact on future legal actions and/or healthcare decisions. A few examples include the suspension of a driving license following an alcohol-related offense, the (legal and societal) consequences that alcohol misuse has for airline pilots and professionals in rehabilitation from alcohol dependence, the legal decisions made concerning the custody of children, or the removal of a patient from the liver transplant list. From a clinical perspective, objectively monitoring alcohol abstinence can substantially improve the monitoring of treatment effectiveness for alcohol-dependent patients. For a full overview of the practical applications, we refer to Pragst and Balikova (2006).

In order to monitor alcohol consumption/abstinence, suitable markers are needed to objectively identify and quantify alcohol consumption. These markers should: (1) differentiate risk drinking from non-risk drinking or abstinence and (2) detect alcohol consumption/abstinence over a long time period (i.e., after complete elimination of alcohol from the body). Currently, both indirect and direct markers are available in this regard. Indirect markers include alanine and aspartate aminotransferase (ALAT and ASAT; Conigrave et al., 2003), gamma-glutamyltransferase (GGT; Hietala et al., 2005), blood count indices (mean corpuscular volume or MCV; Tønnesen et al., 1986), and carbohydrate-deficient transferrin or CDT (van Pelt, 1997; Sharpe, 2001) measures. These techniques are widely available and relatively inexpensive, but show low specificity and sensitivity for the detection of alcohol consumption (see Table 1). Combining these markers can increase specificity up to 94\% (Anton et al., 2002; Majhi et al., 2006; Rinck et al., 2007), but these markers are not specific to alcohol and can be influenced by many factors including, for example, gender, age, and comorbid disorders that elevate enzyme levels but which are not related to alcohol consumption per se (Conigrave et al., 2003; Rinck et al., 2007).

More specific alternatives have focused on direct markers (i.e., ethanol and direct products of alcohol metabolism including phosphatidylethanol (P-Eth), ethyl glucuronide (EtG), ethyl sulfate (EtS), and ethyl esters (FAEEs)) that are present only when alcohol has been consumed. In regard of direct markers assessed in blood and urine, the highest sensitivity was observed for P-Eth (up to 99\%; Aradottir et al., 2006). While direct alcohol markers can be assessed in blood or urine, these have relatively narrow detection windows (e.g., $15 \mathrm{~h}$ for the detection of ethanol in urine; Sarkola et al., 2003). In contrast, hair can serve as a long-term reservoir of ingested foreign substances or their metabolites, such that alcohol consumption can be detected over a much longer time period (months to years dependent on the available hair length).

Ethyl glucuronide (EtG) is a non-volatile, non-oxidative, hydrophilic, and stable alcohol phase II metabolite with a molecular weight of $222 \mathrm{~g} / \mathrm{mol}$. EtG is produced through glucuronidation by UDP-glucurontransferase following ethanol exposure, resulting in the addition of a glucuronic acid moiety to the ethanol molecule. It was first detected in rabbit urine in 1952 (Kamil et al., 1952) and 15 years later in rat and human urine (Jaakonmaki et al., 1967). In 1994, EtG was detected as a stable metabolite in hair after repeated alcohol consumption (Aderjan et al., 1994) and was proposed as a stable marker in hair to detect and quantify alcohol consumption (Høiseth et al., 2007; Skopp et al., 2000; Wurst et al., 2003). With the exception of P-Eth, other direct markers, including ethyl sulphate and four fatty acid ethyl esters (FAEEs; Auwärter et al., 2001; Wurst et al., 2004; Süsse et al., 2010), are also demonstrated in hair. However, compared to concentrations of EtG in hair, concentrations of FAEEs correlate to a lesser extent with the consumed volume of alcohol or with values from other biomarkers (Auwärter et al., 2001; Wurst et al., 2004) and, as proposed by the Society of Hair Testing (SoHT), a positive EtG result ( $>7 \mathrm{pg} / \mathrm{mg}$ EtG in hair) should be the first choice in alcohol abstinence assessment ( $\mathrm{SoHT}$, 2013).

Until recently, the routine use of EtG detection in hair to quantify alcohol consumption was hindered by the then available techniques which had low sensitivity for EtG detection. Less than $0.05 \%$ of the consumed alcohol is metabolized to EtG in urine (Dahl et al., 2002). EtG is excreted mainly in urine and, as a consequence, only small amounts of EtG are incorporated into hair (in the range of picograms per $\mathrm{mg}$ of hair) and sensitive analytical methods are thus necessary to reliably detect EtG concentrations. While the earlier techniques had sensitivities around $20-50 \mathrm{pg} / \mathrm{mg}$ hair (Janda et al., 2002), more recent techniques have improved the sensitivity to close to $0.7 \mathrm{pg} / \mathrm{mg}$ hair (Kerekes et al., 2009). However, while the techniques for EtG detection in hair have significantly improved, no standardized protocols have yet emerged. Protocols vary in sample preparation, extraction procedures, and chromatographic analysis (Maenhout et al., 2013). Additionally, data interpretation is hampered by variables which can affect results.

This review provides (1) an overview of the current techniques for hair analysis of EtG and the possible pitfalls related to data interpretation; (2) an overview of the clinical and forensic studies using EtG level determination in hair as a marker for abstinence, non-risk drinking, and risk drinking; and (3) suggestions for future studies using EtG hair analysis. 
Table 1

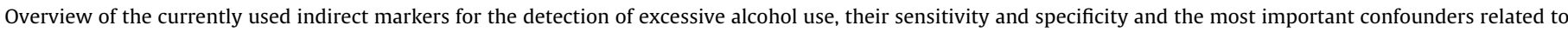
data interpretation.

\begin{tabular}{|c|c|c|c|c|}
\hline Indirect markers & Sensitivity & Specificity & Elimination rate ${ }^{a}$ & Confounders \\
\hline ALAT/ASAT ratio & $<40 \%$ & $90-95 \%$ & $2-3$ weeks & Age, gender, ethnicity, obesity, liver damage, medication use, exercise/sports ${ }^{\mathrm{b}, \mathrm{c}}$ \\
\hline GGT & $30-60 \%$ & $60-95 \%$ & 2-3 weeks & Age, gender, ethnicity, obesity, liver damage and drug history ${ }^{\mathrm{b}, \mathrm{d}, \mathrm{f}}$ \\
\hline MCV & $<50 \%$ & $75-95 \%$ & $2-4$ months & Age, gender, liver damage/disease, drinking regularity, malnutrition ${ }^{\mathrm{b}, \mathrm{d}}$ \\
\hline CDT & $20-85 \%$ & $80-95 \%$ & $2-3$ weeks & Age, gender, ethnicity, comorbid disorders ${ }^{\mathrm{d}, \mathrm{e}, \mathrm{f}}$ \\
\hline
\end{tabular}

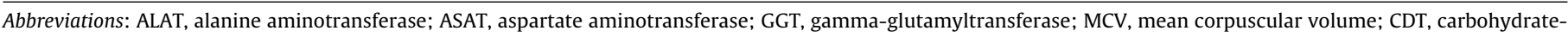
deficient transferrin.

a Ref. Niemelä (2007).

b Ref. Conigrave et al. (2003).

c Ref. Majhi et al., 2006.

d Ref. Sharpe (2001).

e Ref. van Pelt (1997).

f Ref. Anton et al. (2002).

\section{Literature search}

Articles related to EtG analysis techniques and the use of EtG in relation to the detection and quantification of alcohol consumption were searched in PubMed and Web of Science from January 1980 up to August 2013. Articles were manually checked on content and then further checked for cross-references. Sixty-nine articles were limited to the English language, including method; method validation; and preclinical, clinical, and forensic studies using the (combination of) search terms 'EtG', 'ethyl glucuronide', 'alcohol', 'alcoholism', and 'hair'.

For Section 3 (Techniques for the determination of EtG in hair), 19 articles including (1) a detailed description of hair EtG analysis methodology and (2) validation data of the described analytical method, were selected and summarized.

For Section 4 (Data interpretation), 23 clinical and preclinical research articles on the topic of hair EtG, with the exception of the articles describing methodology in Section 3, were selected and interpreted. Review articles, opinions, and case-reports were excluded.

For Section 5 (EtG as a marker for the detection of alcohol consumption), 11 studies were included that (1) report hair EtG concentrations in human alcohol consumers and (2) include data of self-reported alcohol consumption or detailed medical records on drinking behavior. In addition, articles had to include one of two following criteria: (3a) include a comparison group of nonalcohol consuming individuals or ( $3 \mathrm{~b})$ investigate the correlation between hair EtG concentrations and consumed alcohol volumes in a group of alcohol consumers. Method validation studies and studies comparing hair EtG markers with other alcohol markers were excluded in Section 5, with the exception of studies which included data of (self-) reported alcohol consumption. Three studies reporting on hair EtG in alcohol consumers were excluded; two due to a lack of information on volumes of alcohol consumed, and one that included no control group and no correlation analysis between alcohol consumption and hair EtG concentrations.

\section{Techniques for the determination of ethyl glucuronide in hair}

The SoHT has published a consensus regarding hair testing for "chronic excessive alcohol consumption" (i.e., corresponding to an average consumption of $60 \mathrm{~g}$ of pure ethanol per day over several months) and for abstinence assessment (SoHT, 2013; Cooper et al., 2012). The SoHT recommends a threshold level of $30 \mathrm{pg} / \mathrm{mg}$ hair measured in the proximal $6 \mathrm{~cm}$ portion to conclude chronic excessive alcohol consumption ( $>60 \mathrm{~g}$ alcohol per day; Kintz, 2012; Cooper et al., 2012). To distinguish between abstinence and non-risk drinking (10-40 g alcohol per day), a $7 \mathrm{pg} / \mathrm{mg}$ hair threshold level has been proposed (Albermann et al., 2012a;
Pragst and Yegles, 2008; Schubert and Mattern, 2009). A concentration $\geq 7 \mathrm{pg} / \mathrm{mg}$ EtG in the $0-3$ up to $0-6 \mathrm{~cm}$ proximal scalp hair segment strongly suggests repeated alcohol consumption. A lower concentration should not be considered a contradiction to the selfreported abstinence of a person during the corresponding time period before sampling (consensus of the SoHT).

Because of these low concentrations ( $\mathrm{pg} / \mathrm{mg}$ ) of a polar, low-mass compound in a rather complex keratin matrix, the determination of EtG in hair has some serious analytical challenges. Therefore, effective sample preparation steps have been developed and have been coupled with sensitive analytical detection techniques based on gas chromatography-mass spectrometry (GC-MS), gas chromatography-tandem mass spectrometry (GC-MS/MS), or liquid chromatography-tandem mass spectrometry (LC-MS/MS; Table 2).

\subsection{Sample preparation}

After collection, hair samples need a washing procedure to remove possible external contamination of EtG. As can be seen in Table 2, this is often done by sequential washing steps with solvents of different polarity (water, methanol, acetone, dichloromethane, ether, and heptane). Different solvents are used between laboratories, and comparison between washing procedures should be investigated to assess the most efficient washing procedure. After drying of the samples, the hair is then cut into small pieces or ground into a powder in a ball mill to enhance the extraction recovery. When hair is cut rather than ground, the surface area from which EtG can be extracted is much smaller. In general, but especially when using smaller hair samples, the extraction recovery could be significantly improved by grinding of hair compared to cutting. Indeed, studies show significantly higher EtG concentrations in pulverized versus cut hair samples (Albermann et al., 2012a; Mönch et al., 2013). After cutting or grinding, the sample is accurately weighed and should include $30-50 \mathrm{mg}$ of hair, depending on the procedure. For quantification purposes, a deuterated internal standard $\left(d_{5}-E t G\right)$ is added to the sample. EtG is then extracted from the hair matrix by adding a suitable extraction solvent, based on deionized water, and applying incubation and/or ultrasonication (Table 2). As an alternative, Alvarez et al. (2009) proposed microwave-assisted extraction as a simpler and faster procedure. After extraction, the samples are centrifuged and the liquid phase is then processed in different ways (Table 2).

(i) Most protocols include a clean-up based on solid-phase extraction (SPE). Oasis MAX (Waters), Isolute $\mathrm{NH}_{2}$ (Biotage), and Cleanscreen EtG (UCT) sorbents are reported to be suitable for the SPE clean-up of EtG from hair samples.

(ii) Due to the non-volatile character of EtG, derivatization is required for GC-MS or GC-MS/MS. In the literature, 
Table 2

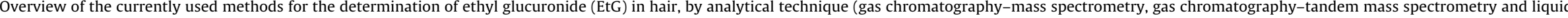

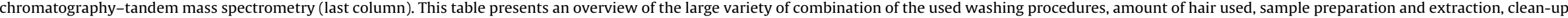
derivatization and limit of quantification used in different studies to assess EtG in hair.

\begin{tabular}{|c|c|c|c|c|c|c|c|c|}
\hline References & Washing procedure & $\begin{array}{l}\text { Amount of hair } \\
\text { used (mg) }\end{array}$ & $\begin{array}{l}\text { Cut or } \\
\text { ground }\end{array}$ & Extraction & Clean-up & Derivatization & $\begin{array}{l}\text { Limit of quantification } \\
(\mathrm{pg} / \mathrm{mg})\end{array}$ & Technique \\
\hline Skopp et al. (2000) & $5 \mathrm{~mL}$ ether, $5 \mathrm{~mL}$ acetone & 50 & Ground & $\begin{array}{l}0.25 \mathrm{~mL} \text { deionised water, } 1 \mathrm{~mL} \\
\text { methanol ( } 5 \mathrm{~h} \text { incubation, } 3 \mathrm{~h} \\
\text { ultrasonication) }\end{array}$ & None & MSTFA & 5000 & GC-MS EI \\
\hline Alvarez et al. (2009) & $\begin{array}{l}5 \mathrm{~mL} 0.1 \% \text { Tween in deionised } \\
\text { water, } 5 \mathrm{~mL} \text { deionised water }\end{array}$ & 100 & Cut & $\begin{array}{l}8 \mathrm{~mL} \text { hexane/deionised water } \\
(1 / 1, \mathrm{v} / \mathrm{v})(11 \mathrm{~min} \text { microwave at } \\
\left.110^{\circ} \mathrm{C}\right)\end{array}$ & None & BSTFA & 300 & GC-MS EI \\
\hline Yegles et al. (2004) & Deionised water, heptane & 30 & Ground & $\begin{array}{l}2 \mathrm{~mL} \text { deionised water }(2 \mathrm{~h} \\
\text { ultrasonication) }\end{array}$ & Isolute $\mathrm{NH}_{2} \mathrm{SPE}$ & PFPA & 6 & GC-MS NICI \\
\hline Kerekes et al. (2009) & Deionised water, acetone & 30 & Ground & $\begin{array}{l}2 \mathrm{~mL} \text { deionised water }(2 \mathrm{~h} \\
\text { ultrasonication) }\end{array}$ & Oasis MAX SPE & PFPA & 2.3 & GC-MS NICI \\
\hline Paul et al. (2011) & Methanol & 20 & Cut & $\begin{array}{l}1 \mathrm{~mL} \text { deionised water (overnight } \\
\text { ultrasonication) }\end{array}$ & Oasis MAX SPE & BSTFA & 10 & GC-MS/MS EI \\
\hline Shi et al. (2010) & $\begin{array}{l}\text { Deionised water, } \\
\text { dichloromethane, methanol }\end{array}$ & 20 & Cut & $\begin{array}{l}1 \mathrm{~mL} \text { deionised water }(1 \mathrm{~h} \\
\text { ultrasonication, incubation } \\
\text { overnight at room temperature) }\end{array}$ & Protein precipitation plate & BSTFA & 10 & GC-MS/MS EI \\
\hline Kharbouche et al. (2009) & Deionised water, acetone & 30 & Ground & $\begin{array}{l}1 \mathrm{~mL} \text { deionised water }(2 \mathrm{~h} \\
\text { ultrasonication) }\end{array}$ & Oasis MAX SPE & PFPA & 8.4 & GC-MS/MS NICI \\
\hline Agius et al. (2010) & $\begin{array}{l}2 \mathrm{~mL} \text { deionised water, } 2 \mathrm{~mL} \\
\text { acetone }\end{array}$ & $10-50$ & Ground & $\begin{array}{l}2 \mathrm{~mL} \text { deionised water }(2 \mathrm{~h} \\
\text { ultrasonication) }\end{array}$ & Cleanscreen EtG SPE & HFBA & 2.8 & GC-MS/MS NICI \\
\hline Janda et al. (2002) & Methanol, acetone & 100 & Cut & $\begin{array}{l}1.5 \mathrm{~mL} \text { deionised water, } 3.5 \mathrm{~mL} \\
\text { acetonitrile, } 0.1 \mathrm{~mL} 3 \mathrm{M} \\
\text { hydrochloric acid }(3 \mathrm{~h} \\
\left.\text { ultrasonication at } 50^{\circ} \mathrm{C}\right)\end{array}$ & Isolute $\mathrm{NH}_{2} \mathrm{SPE}$ & & 102 & LC-MS/MS \\
\hline Morini et al. (2006) & $\begin{array}{l}1 \mathrm{~mL} \text { dichloromethane, } 1 \mathrm{~mL} \\
\text { methanol }\end{array}$ & 100 & Cut & $\begin{array}{l}700 \mu \mathrm{L} \text { deionised water } \\
\text { (incubation overnight at room } \\
\text { temperature, } 2 \mathrm{~h} \text { ultrasonication) }\end{array}$ & None & & 3 & LC-MS/MS \\
\hline Kintz et al. (2008) & $10 \mathrm{~mL}$ dichloromethane & 50 & Cut & $\begin{array}{l}2 \mathrm{~mL} \text { deionised water }(2 \mathrm{~h} \\
\text { ultrasonication) }\end{array}$ & Oasis MAX SPE & & 10 & LC-MS/MS \\
\hline Concheiro et al. (2009) & $\begin{array}{l}5 \mathrm{~mL} \text { dichloromethane, } 5 \mathrm{~mL} \\
\text { methanol }\end{array}$ & 100 & Ground & $\begin{array}{l}2 \mathrm{~mL} \text { deionised water }(2 \mathrm{~h} \\
\text { ultrasonication) }\end{array}$ & None & & 50 & LC-MS/MS \\
\hline Lamoureux et al. (2009) & $\begin{array}{l}10 \mathrm{~mL} \text { deionised water, } 10 \mathrm{~mL} \\
\text { dichloromethane }\end{array}$ & 30 & Cut & $\begin{array}{l}2 \mathrm{~mL} \text { deionised water }(2 \mathrm{~h} \\
\text { ultrasonication) }\end{array}$ & Cleanscreen EtG SPE & & 10 & LC-MS/MS \\
\hline Tarcomnicu et al. (2010) & $\begin{array}{l}\text { Deionised water, } \\
\text { dichloromethane }\end{array}$ & 25 & Cut & $\begin{array}{l}1 \mathrm{~mL} \text { deionised water, } 1 \mathrm{~mL} \\
\text { acetonitrile (vortexing, } 16 \mathrm{~h} \\
\text { incubation at room temperature, } \\
90 \text { min ultrasonication) }\end{array}$ & None & & 20 & LC-MS/MS \\
\hline Albermann et al. (2010) & $\begin{array}{l}1 \mathrm{~mL} \text { dichloromethane, } 1 \mathrm{~mL} \\
\text { methanol }\end{array}$ & 100 & Cut & $\begin{array}{l}700 \mu \mathrm{L} \text { deionised water } \\
\text { (incubation overnight at room } \\
\text { temperature, } 2 \mathrm{~h} \text { ultrasonication) }\end{array}$ & None & & 4 & LC-MS/MS \\
\hline Pirro et al. (2011) & $\begin{array}{l}3 \mathrm{~mL} \text { dichloromethane, } 3 \mathrm{~mL} \\
\text { methanol }\end{array}$ & $50 \mathrm{mg}$ & Cut & $\begin{array}{l}700 \mu \mathrm{L} \text { deionised water } \\
\text { (incubation overnigh at room } \\
\text { temperaturet, } 90 \mathrm{~min} \\
\text { ultrasonication) }\end{array}$ & None & & 10 & LC-MS/MS \\
\hline Cabarcos et al. (2012) & $\begin{array}{l}\text { Deionised water, } \\
\text { dichloromethane }\end{array}$ & $100 \mathrm{mg}$ & Cut & $\begin{array}{l}2 \mathrm{~mL} \text { deionised water ( } 15 \mathrm{~min} \\
\text { ultrasonication) }\end{array}$ & Oasis MAX SPE & & 20 & LC-MS/MS \\
\hline Suesse et al. (2012) & $\begin{array}{l}3 \mathrm{~mL} \text { acetone, } 3 \mathrm{~mL} \text { deionised } \\
\text { water }\end{array}$ & $50 \mathrm{mg}$ & Cut & $\begin{array}{l}2 \mathrm{~mL} \text { deionised water, } 3.5 \mathrm{~mL} \\
\text { acetonitrile, } 0.3 \mathrm{~mL} 1 \mathrm{~N} \\
\text { hydrochloric acid }(4 \mathrm{~h} \\
\text { ultrasonication) }\end{array}$ & Isolute $\mathrm{NH}_{2} \mathrm{SPE}$ & & 2.6 & LC-MS/MS \\
\hline Kronstrand et al. (2012) & $\begin{array}{l}1 \mathrm{~mL} \text { methanol, } 1 \mathrm{~mL} \\
\text { dichloromethane }\end{array}$ & $30 \mathrm{mg}$ & Cut & $\begin{array}{l}1.5 \mathrm{~mL} \text { deionised water } \\
\text { (incubation for } 18 \mathrm{~h} \text { at } 37^{\circ} \mathrm{C} \text { ) }\end{array}$ & Cleanscreen EtG SPE & & 2 & LC-MS/MS \\
\hline
\end{tabular}

mass spectrometry; SPE, solid-phase extraction. 
procedures with pentafluoropropionic anhydride (PFPA), heptafluorobutyric anhydride (HFBA), N-Methyl$\mathrm{N}$-(trimethylsilyl) trifluoroacetamide (MSTFA), and N,O-Bis(trimethylsilyl)trifluoroacetamide (BSTFA) have been described (Jurado et al., 2004).

(iii) All protocols use evaporation and reconstitution in a solvent that is suitable for injection in the gas- or liquid chromatographic system.

\subsection{Gas chromatography-mass spectrometry (GC-MS) and gas chromatography-tandem mass spectrometry (GC-MS/MS)}

The first analytical report of EtG in hair was published in 2000 by Skopp and co-workers. They used GC-MS electron impact (EI) and the method had a limit of quantification (LOQ) of $5000 \mathrm{pg} / \mathrm{mg}$. Alvarez et al. (2009) improved the LOQ of the GC-MS in electron impact (EI) mode by a microwave-assisted extraction procedure to $300 \mathrm{pg} / \mathrm{mg}$. An increase in analytical sensitivity was obtained when negative ion chemical ionization mode (NICI) in combination with solid-phase extraction (SPE) clean-up was used. Yegles et al. (2004) and Kerekes et al. (2009) observed LOQs in the low pg/mg range for the determination of EtG in hair with a validated GC-MS NICI method (Table 2).

Tandem mass spectrometry minimizes background interferences and should achieve high sensitivity and selectivity due to the selected reaction monitoring (SRM). GC-MS/MS has therefore been applied for the determination of EtG in hair, both with EI (Paul et al., 2011; Shi et al., 2010) and NICI (Agius et al., 2010; Kharbouche et al., 2009). However, as can be seen from Table 2, there was no significant increase in sensitivity for the GC-MS/MS NICI methods as compared with the GC-MS NICI methods. To the contrary, when EI is used, a significant increase in sensitivity was observed between GC-MS and GC-MS/MS (Cabarcos et al., 2012; Kronstrand et al., 2012; Suesse et al., 2012; see Table 2).

\subsection{Liquid chromatography-tandem mass spectrometry (LC-MS/MS)}

Even though the GC-MS and GC-MS/MS procedures proved to be accurate and sensitive for the determination of EtG in hair, the majority of the published methods are based on LC-MS/MS because of the easier sample preparation and the absence of a derivatization step. However, due to the high polarity of EtG, retention on classical reversed-phase LC (RPLC) columns can only be obtained with a highly aqueous mobile phase. These are not optimal conditions for ionization in the electrospray ionization (ESI) interface of the mass spectrometer, which leads to sensitivity problems. Several solutions have been proposed:

(i) The post-column addition of acetonitrile in RPLC to enhance ionization (Janda et al., 2002; Morini et al., 2006; Albermann et al., 2010).

(ii) The use of hydrophilic interaction liquid chromatography (HILIC) columns which utilize a mobile phase with a high organic content (Kintz et al., 2008; Lamoureux et al., 2009; Tarcomnicu et al., 2010).

(iii) The use of porous graphitic carbon columns (Concheiro et al., 2009).

Janda et al. (2002) published the first method for the determination of EtG in hair based on LC-MS/MS and could measure as low as $102 \mathrm{pg} / \mathrm{mg}$. Morini et al. (2006) developed and validated a method with an LOQ of $3 \mathrm{pg} / \mathrm{mg}$, which is comparable with the LOQs obtained with GC-MS and GC-MS/MS. In recent years, more
LC-MS/MS methods have been published, all with LOQs in the low $\mathrm{pg} / \mathrm{mg}$ range (Table 2 ).

\subsection{Proficiency testing}

In the last few years, several organizations developed services for quality assurance for EtG analysis; e.g., Arvecon (Proficiency Testing Organization ARVECON GmbH, Walldorf, Germany), Medichem (MEDICHEM Dianostica GmbH, Steinenbronn, Germany), or AcqScience (ACQ Science GmbH, RottenburgHailfingen, Germany).

\subsection{Alternative assays}

Potentially, EtG in hair could also be detected using enzyme immunoassays (EIA). EIA techniques are less laborious and less expensive compared to chromatographic techniques. The detection of EtG in hair using immunoassays should be developed and could make EtG testing more accessible and cost-effective.

At the moment, EIA tests have been described for EtG detection in urine and in vitreous humor with an excellent agreement in the frequency of positive EtG samples compared to a LC-MS/MS technique (Böttcher et al., 2008; Rainio et al., 2013), but none are yet available for the detection of EtG in a hair matrix.

\section{Data interpretation}

When interpreting data related to alcohol consumption in terms of health, it is necessary to define "risky" alcohol consumption; i.e., repeated daily alcohol consumption associated with increased chronic disease and mortality. The World Health Organization (WHO) proposed a limit of 14 standard units per week for women (i.e., about $20 \mathrm{~g}$ alcohol per day) and 21 standard units per week for men, with two alcohol-free days per week, to be considered as "risk" drinking (WHO, 2001; Rehm et al., 2003).

In correlating volumes of alcohol consumed to an amount of EtG present in hair, confounders should be taken into account when interpreting data as well as the variability in quantification of EtG in hair. These relate to the hair sample itself, to the incorporation of EtG in hair, or to individual factors that can influence the incorporation of EtG in hair. Apart from differences in sample preparation and analytical techniques, the variables presented in the following subheadings may help explain the sometimes large variability between EtG concentrations in hair samples that are currently observed.

\subsection{Hair length/segmentation}

Depending on the technique, about $30-50 \mathrm{mg}$ hair of sufficient length needs to be available for the accurate detection of EtG levels. The SoHT recommends that EtG values are detected in the $0-6 \mathrm{~cm}$ proximal segment and that, if samples of less than $3 \mathrm{~cm}$ are used, the results should be interpreted with caution (SoHT, 2013). However, segmentation of hair samples (e.g., in $1 \mathrm{~cm}$ segments) can provide time-related information regarding alcohol consumption, monitor abstinence, and provide data regarding relapses for an individual (Appenzeller et al., 2007a; Wurst et al., 2008). If one assumes that scalp hair grows approximately $1 \mathrm{~cm} /$ month (SoHT, 2013), one can compare the history of alcohol consumption to EtG hair concentration levels in the different hair segments. For this purpose, a recent study showed that EtG remains stable in the more distal hair segments up to $12 \mathrm{~cm}$ (Agius et al., 2012).

\subsection{Pigmentation}

Hair pigmentation (i.e., melanin) influences the deposition of drugs in hair. At equal doses, drug levels (e.g., methadone, cocaine) 
are often higher in highly pigmented hair compared to lighter hair (Green and Wilson, 1996; Reid et al., 1996). However, EtG incorporation seems not to be affected by hair pigmentation (Appenzeller et al., 2007b; Kharbouche et al., 2010).

\subsection{Cosmetic treatment}

Hair bleaching, perming and coloring can result in a substantial loss of EtG in hair (Kerekes and Yegles, 2013; Morini et al., 2010; Suesse et al., 2012; Yegles et al., 2004). Moreover, there is no evidence for an increase of EtG after the use of ethanol-containing hair cosmetics (Martins Ferreira et al., 2012). However, the use of an ethanol-containing hair product (i.e., an alcohol-containing plant extract) produced a positive EtG test as this product was revealed to contain EtG (Sporkert et al., 2012). In this regard, EtG was observed in a number of herbal hair tonics from different manufacturers (EtG concentrations ranging from 0.07 to $1.06 \mathrm{mg} / \mathrm{L}$ ), thereby addressing the need of assessing the use of hair care products, especially in individuals who deny alcohol consumption (Arndt et al., 2013). No EtG was present in pure synthetic hair care products (Arndt et al., 2013).

\subsection{Non-head hair}

In situations where scalp hair is not available, hair from alternative body locations could be examined (e.g., pubic, beard, chest, $\mathrm{arm} / \mathrm{leg}$, or axillary hair). While the main route of EtG incorporation into hair is through the bloodstream (Kharbouche et al., 2010), exposure to urine or sweat can contribute to EtG hair incorporation in alcohol consumers. EtG is excreted mainly through the urine and, subsequently, pubic hair exposed to EtG-positive urine will show higher EtG concentrations (Høiseth et al., 2007; Kerekes et al., 2009) as urine can incorporate EtG into hair through diffusion (Kerekes et al., 2009). Because of this, pubic hair analysis is more sensitive when compared to head or other sources of hair. Indeed, higher EtG concentrations were found in pubic hair compared to head hair (Kintz et al., 2008; Kerekes et al., 2009), and, as a consequence, a negative pubic hair result strongly confirms abstinence (consensus of the SoHT). Due to its high sensitivity, pubic hair could be used to distinguish between types of drinkers (risk-drinkers, nonrisk drinkers, and individuals abstaining from alcohol consumption or "teetotallers"). For other hair locations, e.g., samples from the beard, chest, arm/leg, EtG concentrations were similar to head hair (Kerekes et al., 2009; Pianta et al., 2013).

Each individual hair follows a distinct growth cycle and, dependent on the location and type of hair, has a distinct growth rate. For example, pubic hair has a slower growth rate $(0.75 \mathrm{~cm} / \mathrm{month}) \mathrm{com}$ pared to head hair $(1 \mathrm{~cm} / \mathrm{month})$ (SoHT). As a result, a slower hair growth rate leads to higher detected EtG concentrations. Also, hair samples include a portion of non-growing hair, i.e., hair that is in the catagen or telogen phase (Appenzeller et al., 2007b). For scalp hair, approximately $15 \%$ of hairs are in resting phases and these phases last up to 4 months, after which a new hair starts to grow (Harkey, 1993). Hair from other body locations have longer resting phases (up to 2-6 years) and include a different percentage of hairs that are in resting phases, with a main rule of longer resting phases in longer hairs (Harkey, 1993). This implies that growth rate and duration of resting phases are of key importance in the interpretation of results from hair from different body locations and one cannot substitute scalp hair with other hair for the detection of EtG over time in one individual.

\subsection{Alcohol consumption profile}

In order to differentiate between alcohol consumption and abstinence using EtG levels, and assuming the techniques have sufficient sensitivity to detect EtG levels, a linear relationship should be observed. Considering the clinical, ethical, and logistic issues in the controlled study of alcohol consumption in human subjects, the use of animal models is a good alternative to determine the relationship between EtG levels in hair and the consumption of alcohol. Rats do not have sweat glands, thereby reducing one variable seen in humans, i.e., the impregnation of hair by EtGcontaining sweat. In male rats receiving $0,1,2$, or 3 g ethanol $/ \mathrm{kg}$ body weight over 4 weeks, EtG concentrations in hair increased in a dose-dependent manner, with a positive correlation between EtG concentrations in hair and in blood (Pearson's $r=0.89 ; p<0.001$; Kharbouche et al., 2010). In another study in which rats were given a $10 \%$ alcohol solution over a 4 -week period, a strong correlation was observed between the amount of consumed alcohol and the resulting EtG levels in hair from female rats (correlation Spearman's $r=0.71 ; p<0.001)$, but not in males $(r=0.23 ; p=0.28$, NS) (Małkowska et al., 2012). In human studies, correlation between EtG hair concentration and alcohol consumption was also observed (e.g., Appenzeller et al., 2007a; Kerekes et al., 2009; Politi et al., 2006). These studies are discussed in detail later.

Drinking behavior has been hypothesized to play a role in the incorporation of EtG in hair due to differences in the time of exposure to blood EtG. Pragst and Balikova (2006) proposed that the area under the curve of ethanol in plasma correlates the best with the amount of EtG incorporated in hair. Since the time of exposure and concentration of ethanol in plasma differs with drinking behavior, it is conceivable that drinking behavior may be a crucial variable for EtG incorporation and thus EtG concentration in human hair. Unfortunately, there are no studies which have investigated alcohol drinking patterns and the incorporation of EtG into hair.

\subsection{Alcohol metabolism}

The time of exposure to blood EtG is an important variable in determining the amount of EtG incorporated in hair. Blood EtG concentration, however, is strongly dependent on an individual's metabolism (i.e., alcohol uptake, metabolism, and excretion). The most important variables related to alcohol metabolism are gender differences and age. Gender differences in alcohol uptake and elimination (Li et al., 2000) can be related to sex hormone levels, as testosterone has been shown to decrease ethanol metabolism rates (Rachamin et al., 1980) and progesterone has been found to increase metabolism rates (Dettling et al., 2008). In men, ethanol metabolizes at $0.15 \mathrm{~g} / \mathrm{L}$ per hour, while in women, a faster metabolization rate of $0.17 \mathrm{~g} / \mathrm{L}$ per hour is observed (Jones, 2010). This would result in differences in the deposition of EtG between male and females. Gender differences regarding EtG deposition in hair have been observed in rats (Małkowska et al., 2012). Another important factor that contributes to individual differences in alcohol metabolism/excretion is age, where elimination decreases with age (Seitz et al., 1992). Other confounders include physiological differences, such as differences in liver volume (Kwo et al., 1998), enzyme levels (e.g., liver alcohol dehydrogenase; Neumark et al., 2004), and pregnancy (Shankar et al., 2007). Due to their effect on alcohol metabolism, these factors play a role in the hair deposition of EtG and should be taken into account. More research is needed on this behalf to better define these relationships.

\subsection{Pathophysiological changes}

Uridine 5'-diphospho-glucuronosyltransferases (UDPglucuronosyltransferases or UGTs) are enzymes responsible for the biosynthesis of saccharides. EtG is formed by conjugation of ethanol through UGTs (Foti and Fisher, 2005), thus, differences in UGT levels due to genetics and/or an underlying pathophysiology can be responsible for variation in EtG levels. Gilbert's syndrome 
Table 3

Overview of the currently available studies assessing hair EtG levels in alcohol dependent patients and social drinkers, not including method validation studies.

\begin{tabular}{|c|c|c|c|c|}
\hline Study & Subjects $(N)$ & EtG range (pg/mg) & $\begin{array}{l}\text { Author's recommendations } \\
\text { for cut-off value }\end{array}$ & LOD (pg/mg) \\
\hline Alt et al. (2000) & $\begin{array}{l}\text { Risk drinkers/alcohol dependent PM (16) } \\
\text { Risk drinkers (4) } \\
\text { Non-risk drinkers (6) } \\
\text { Children/control group (5) }\end{array}$ & $\begin{array}{l}\text { nd-4025 } \\
119-388 \\
\text { nd } \\
\text { nd }\end{array}$ & - & Not provided \\
\hline Skopp et al. (2000) & $\begin{array}{l}\text { Risk drinkers PM (4) } \\
\text { Non-risk drinkers PM ( } 7 \text { ) } \\
\text { Children/control group (3) }\end{array}$ & $\begin{array}{l}\text { nd- }<5 \\
\text { nd-13.8 } \\
\text { nd }\end{array}$ & - & 2.2 \\
\hline Janda et al. (2002) & $\begin{array}{l}\text { PM samples (27) } \\
\text { Risk drinkers/alcohol dependent (60) } \\
\text { Non-risk drinkers (5) } \\
\text { Children/control group (5) }\end{array}$ & $\begin{array}{l}\text { nd-13157 } \\
\text { nd-984 } \\
\text { nd-55 } \\
\text { nd }\end{array}$ & - & 51 \\
\hline Yegles et al. (2004) & $\begin{array}{l}\text { Risk drinkers/alcohol dependent (10) } \\
\text { Non-risk drinkers (4) } \\
\text { Teetotallers (3) }\end{array}$ & $\begin{array}{l}30-415 \\
\text { nd } \\
\text { nd }\end{array}$ & - & 2 \\
\hline Politi et al. (2006) & $\begin{array}{l}\text { Risk drinkers/alcohol dependent (22) } \\
\text { Consuming } 2 \text { to } 60 \mathrm{~g} / \text { day alcohol (21) } \\
\text { Teetotallers ( } 7 \text { ) }\end{array}$ & $\begin{array}{l}4-434 \\
\text { nd-35 } \\
\text { nd }\end{array}$ & $\begin{array}{l}\mathrm{EDI}>30 \mathrm{~g}: 4 \mathrm{pg} / \mathrm{mg} \\
\mathrm{EDI}>40 \mathrm{~g}: 5 \mathrm{pg} / \mathrm{mg}\end{array}$ & 2 \\
\hline Appenzeller et al. (2007b) & Risk drinkers/alcohol dependent (15) & $8-261$ & $\begin{array}{l}\text { EDI } 11-40 \mathrm{~g}: 4-15 \mathrm{pg} / \mathrm{mg} \\
\text { EDI > } 60 \mathrm{~g}: 23 \mathrm{pg} / \mathrm{mg}\end{array}$ & 2 \\
\hline Kerekes et al. (2009) & Risk + non-risk drinkers (32) & nd-1146 & - & 0.7 \\
\hline Kronstrand et al. (2012) & $\begin{array}{l}\text { Consuming } 32 \mathrm{~g} \text { alcohol for } 3 \text { months ( } 7 \text { ) } \\
\text { Consuming } 16 \mathrm{~g} \text { alcohol for } 3 \text { months (14) } \\
\text { Non-drinking control group ( } 23 \text { ) }\end{array}$ & $\begin{array}{l}\text { nd-11 } \\
\text { nd-3 } \\
\text { nd }\end{array}$ & $\begin{array}{l}\text { EDI } 16 \mathrm{~g}:<\text { SoHT, } 7 \mathrm{pg} / \mathrm{mg}^{\mathrm{a}} \\
\text { EDI } 32 \mathrm{~g}:<\text { SoHT, } 30 \mathrm{pg} / \mathrm{mg}^{\mathrm{a}}\end{array}$ & 2 \\
\hline Kharbouche et al. (2012) & $\begin{array}{l}\text { Risk drinkers }(38) \\
\text { Non-risk drinkers }(44) \\
\text { Teetotallers }(43)\end{array}$ & $\begin{array}{l}\text { nd-1190 } \\
\text { nd-32 } \\
\text { nd }\end{array}$ & $\begin{array}{l}\text { EDI > } 20 \mathrm{~g}: 9 \mathrm{pg} / \mathrm{mg} \\
\mathrm{EDI}>60 \mathrm{~g}: 25 \mathrm{pg} / \mathrm{mg}\end{array}$ & 2 \\
\hline Stewart et al. (2013) & $\begin{array}{l}\text { Liver transplant patients: } \\
\text { Non-alcohol consuming ( } 82) \\
\text { Consuming average of }<28 \mathrm{~g} / \text { day alcohol }(57) \\
\text { Consuming average of }>28 \mathrm{~g} / \text { day alcohol }(52)\end{array}$ & $\begin{array}{l}\text { nd (only } 1 \text { positive) } \\
\text { M (IQR): } 0(0-10) \\
\text { M (IQR): } 100(31-187)\end{array}$ & $\mathrm{EDI}>28 \mathrm{~g}: 8 \mathrm{pg} / \mathrm{mg}$ & 2 \\
\hline
\end{tabular}

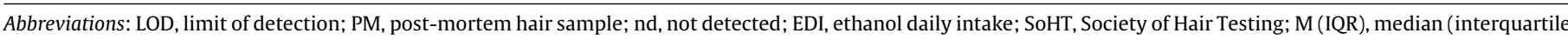
range).

a Below recommendations of the Society of Hair Testing cut-off values.

occurs in $5 \%$ of the population and is characterized by increased bilirubin levels due to a deficiency of UGT. As a result of the UGT deficiency, lower EtG levels are supposed. Higher levels of EtG in hair have also been observed in patients with decreased kidney function (Høiseth et al., 2013).

\section{ETG as a marker for the detection of alcohol consumption}

The following is an overview on the available studies that have used EtG hair testing for the quantification of alcohol consumption. An overview of the studies described in the subsequent paragraphs and the detected EtG levels are presented in Table 3.

\subsection{Quantification of EtG in alcohol consumers}

Several early studies showed that EtG could be detected in hair from individuals with a known history of alcoholism. Alt et al. (2000) detected EtG levels in hair samples obtained from in-treatment alcohol-dependent patients, but not in hair of nonrisk drinkers (consuming up to $20 \mathrm{~g}$ alcohol daily). In a study by Skopp et al. (2000) with a method with a low limit of detection of $2.2 \mathrm{pg} / \mathrm{mg}$ (see Table 3), post-mortem hair samples of alcoholdependent individuals showed undetectable EtG levels in 2 out of 4 samples. Hair samples from non-risk alcohol consumers showed either negative EtG levels or levels very close to the LOD (Skopp et al., 2000). In a larger study, Janda et al. (2002) detected EtG levels in post-mortem hair from individuals with a known history of alcohol dependence in over $80 \%$ of the cases. In alcohol-dependent patients, EtG was detected in 55\% of the samples. Again, in nonrisk drinkers consuming up to $30 \mathrm{~g} /$ day, EtG was only detected in 1 of 5 individuals (EtG: $55 \mathrm{pg} / \mathrm{mg}$; Janda et al., 2002). The main limitations of this study relate to the high LOQ of the analytical method used at that time $(51 \mathrm{pg} / \mathrm{mg})$. Also, no information on the time of autopsy was available, no information regarding the amount of alcohol consumption was available, and less than $15 \mathrm{mg}$ of hair was used in a large portion of samples where no EtG was detected. Thus, the reliability and interpretation of this study should be questioned, specifically when interpreting the negative findings in non-risk drinkers. Yegles et al. (2004) detected EtG levels using a new technique (LOD $2 \mathrm{pg} / \mathrm{mg}$ ) in currently treated alcohol-dependent patients, while no EtG levels were detected in teetotallers. The authors conclude that EtG is a suitable marker for risk drinking (Yegles et al., 2004).

\subsection{Correlation between EtG levels and volumes of alcohol consumed}

In an early study, Skopp et al. (2000) found no correlation between drinking behavior, assessed using medical records and eyewitnesses, and EtG hair concentrations. In contrast, Politi et al. (2006) observed a significant correlation between EtG hair concentrations and daily alcohol consumption assessed using a drinking questionnaire (Politi et al., 2006). From these results, the authors suggested cut-off values of 4 and $5 \mathrm{pg} / \mathrm{mg}$ to detect (individuals consuming $>30 \mathrm{~g}$ alcohol/day and $>40 \mathrm{~g}$ alcohol/day (Politi et al., 
2006). In a study by Appenzeller et al. (2007b) EtG hair values were compared to the patients' self-reported drinking history. In most samples (13 out of 15), the EtG concentration patterns were consistent with the self-reported history of alcohol consumption (Pearson's $r=0.54 ; p=0.039$ ). Following the exclusion of 5 patients because of discolored hair and unreliable self-reports of alcohol consumption, the correlation between EtG in hair and alcohol consumption increased significantly (Pearson's $r=0.84 ; p<0.001$ ). In addition, periods of abstinence and relapses could be observed when using segmented hair samples, but only when the hair was sampled more than 1 month after drinking cessation (Appenzeller et al., 2007b). It should be noted that, in contrast to previous studies, segmented hair samples were used with lengths around $0.5-1 \mathrm{~cm}$. This approach would have improved the precision of timing and quantification significantly, and should be considered in future clinical or forensic toxicology. Kerekes et al. (2009) reported EtG concentrations in hair that were significantly correlated with daily alcohol consumption in non-risk drinkers (10-40 g/day) and risk drinkers ( $>60 \mathrm{~g} /$ day) (Spearman $r=0.89 ; p<0.001$; Kerekes et al., 2009). However, one recent study is in contrast with the earlier observed correlations between EtG levels and alcohol consumption volumes (Kronstrand et al., 2012). Only 4 of 7 participants ingesting $32 \mathrm{~g}$ alcohol daily during 3 months had measurable EtG levels in hair. With the exception of one participant, consumption of $16 \mathrm{~g}$ alcohol daily during 3 months did not provide detectable EtG levels. As a result of these data, the authors proposed that a lower threshold level than the current $30 \mathrm{pg} / \mathrm{mg}$ suggested by the SoHT should be considered. A few study limitations should be noted here, especially regarding the study design and methodology. Specifically, all participants consuming $16 \mathrm{~g}$ alcohol daily were female and all participants consuming $32 \mathrm{~g}$ alcohol daily were male. Given the importance of gender differences on alcohol metabolism and EtG incorporation, females/males should be balanced in such studies or should be chosen to include one sex only for group comparison purposes. Additionally, the EtG peak will have been low due to the low sample weights (ranging from 6 to $26 \mathrm{mg}$, mean $16 \mathrm{mg}$ ) and due to the extraction procedure which used cut samples. These have been shown to be less potent than ground samples (Albermann et al., 2012b).

In one of the larger studies including 200 patients with liver disease, EtG in hair was a highly accurate indicator for detecting alcohol consumption higher than $28 \mathrm{~g}$ alcohol per day using a cutoff of $15 \mathrm{pg} / \mathrm{mg}$ hair (Stewart et al., 2013). There was a slight influence of gender and liver cirrhosis on EtG hair values and a correlation was found between EtG values and reported drinking during the prior 90 days (Spearman $r=0.38 ; p<0.001$ ). Based on data from 125 subjects, Kharbouche et al. (2012) proposed a cutoff value of $9 \mathrm{pg} / \mathrm{mg}$ to detect risk-drinking ( $>20 / 30 \mathrm{~g}$ per day) and $25 \mathrm{pg} / \mathrm{mg}$ to detect chronic excessive alcohol consumption ( $>60 \mathrm{~g}$ ).

Results from clinical and forensic studies of teetotallers are consistent in reporting negative EtG levels (Alt et al., 2000; Janda et al., 2002; Kharbouche et al., 2012; Kronstrand et al., 2012; Politi et al., 2006; Skopp et al., 2000; Stewart et al., 2013; Yegles et al., 2004). As presented above, results from EtG hair analysis in risk and nonrisk drinkers show much variation. In older studies (Alt et al., 2000; Janda et al., 2002), this can be explained by the technique's relatively high LOQ. In studies with lower LOQs, other factors should be considered. First, gender differences are often not taken into account in studies that aim to correlate volumes of ingested daily alcohol with EtG levels. Second, pathophysiological conditions (e.g., Gilbert's syndrome that occurs in approximately 1 out of 20 individuals) are not reported or controlled for. Third, self-reported alcohol consumption can be biased in at-risk alcohol users (Sobell et al., 1997; Toneatto et al., 1992). The latter may be especially important in groups where alcohol consumption has serious consequences for further health care (e.g., liver transplant patients), but this might also be the case for alcohol-dependent patients currently in treatment. In summary, in spite of the variation, a linear correlation is observed between alcohol consumption (volume) and detected EtG levels in hair (Appenzeller et al., 2007b; Kerekes et al., 2009; Politi et al., 2006).

\section{Summary and conclusions}

There are several published analytical methods for the determination of EtG in hair which have different sample preparation steps and detection methods. It might be desirable to have a standardized protocol for the measurement of EtG concentrations in hair. However, considering the findings of the present review, it is the opinion of the authors that this is not necessary. The existence of different analytical protocols is not a problem, as long as the method employed performs well in proficiency programs.

We conclude that the detection of EtG in hair has substantial advantages compared to routine methods of alcohol detection in urine or blood, largely because EtG can be detected over much longer time periods (months to years dependent on the available hair length) compared to blood and urine, and obtaining hair samples is non-invasive with easy storage conditions.

Regarding possible pitfalls for data interpretation, a variety of factors should be taken into account, including gender, age, drinking pattern, hair length, hair bleaching and other cosmetic treatments, pregnancy, and pathophysiology such as Gilbert's syndrome and kidney function. While these play a negligible role in the repeated analysis of EtG values for the same individual (e.g., for forensic purposes or when detecting alcohol use during addiction treatment), these should be considered when interpreting data from studies for group comparison purposes. While studies often describe factors as age, gender, and previous hair treatment and color, limited information is often provided regarding other factors such as pathophysiology and drinking patterns. Additionally, even when detailed information is provided on these differences, studies do not adequately focus on matching patient subpopulations as to these variables (e.g., Kronstrand et al., 2012). With this, it is difficult to disentangle the effects of, e.g., gender and daily ingested alcohol volume on EtG levels in hair. While almost all studies mention the possible effects of these variables on the interpretation of their data, only a few studies have attempted to normalize the data to include body weight (Politi et al., 2006) and only participants with non-colored hair (Skopp et al., 2000). Also, many studies have used small amounts of hair and, as such, the interpretation of their results is ambiguous when lower alcohol consumption volumes are expected such as in non-risk drinkers. Finally, while many of the cited studies were evaluated for correlations between EtG levels and daily alcohol consumption, this was hampered by a lack of detailed descriptions of alcohol drinking patterns.

In general, more studies are needed which have consistent methodology and sample preparation for larger samples in order to assess: (1) the relationship between EtG hair levels and daily alcohol consumption; (2) the influence of separate (individual) variables and how to account for them in future studies; and (3) the appropriate cutoff values to distinguish risk drinking from non-risk drinking and teetotallers. For future studies, we propose to combine EtG hair level detection with controlled alcohol consumption conditions, with control for gender, age, pathophysiology, and cosmetics use. This should be performed in relatively large cohorts ( $>50$ participants per group) such that remaining confounding factors could be set as covariates in statistical analysis.

A first step toward distinguishing between risk and non-risk drinking based on EtG quantification data, is providing an accurate 
description of risk and non-risk drinking. A definition is presented by the WHO (where risky drinking is set to be at $>20 \mathrm{~g}$ alcohol/day for women and $30 \mathrm{~g}$ alcohol/day for men) as a criterion related to all-cause mortality and chronic disease. This criterion is often used and already takes into account gender differences. Therefore, we recommend that these WHO criteria should be explicitly used in future studies to separate risk- and non-risk alcohol consumption. Using these criteria should allow better, and probably lower, cutoff values than those currently proposed by the SoHT $(7 \mathrm{pg} / \mathrm{mg}$ and $30 \mathrm{pg} / \mathrm{mg}$ as a cutoff for abstinence assessment and chronic excessive alcohol consumers, respectively). Boscolo-Berto et al. (2013) came to a similar conclusion in their recent meta-analysis, concluding that the cut-off of $30 \mathrm{pg} / \mathrm{mg}$ proposed by the SoHT limits the false-negative effect of differentiating risk- from non-risk drinkers, while the $7 \mathrm{pg} / \mathrm{mg}$ cut-off value might only be used for suspecting an active alcohol use rather than providing evidence for complete abstinence. Also, due to e.g., variables that can affect EtG hair levels, some studies propose to use lower cutoffs than the ones currently implemented. Different studies propose cutoff values for risk-drinking with an upper limit ( $>28 \mathrm{~g}$ but $<40 \mathrm{~g}$ alcohol daily; termed "moderate drinking" in a few studies) between $4 \mathrm{pg} / \mathrm{mg}$ and 15 pg/mg (Politi et al., 2006; Stewart et al., 2013; Kharbouche et al., 2009). Other studies propose lower cutoff values between $4 \mathrm{pg} / \mathrm{mg}$ (Politi et al., 2006) and 25 pg/mg (Kharbouche et al., 2012) to assess risk drinking exceeding $40 \mathrm{~g}$ of alcohol per day. In conclusion, more research is needed to provide reliable interpretation of cutoff values to differentiate use from its abuse. This can only be achieved by using the vast set of criteria regarding the interpretation of risk drinking (as proposed by WHO) with respect to gender differences.

The contribution of this review is the detailed description of the currently used methodologies for EtG detection in combination with the current research knowledge using EtG for the quantification of alcohol consumption. The review provides an understanding of the differences in methodology and the confounding factors that may contribute to the relatively large variance observed in EtG values in alcohol consumers. The number of EtG assay articles has increased rapidly over the last 5 years. Many variations in techniques are available, thereby providing a need for an accurate and detailed overview of the currently used techniques for EtG quantification in hair. Available studies of EtG levels in hair for different groups of alcohol consumers often use different methodologies for sample preparation. Even though these studies utilize assay methods with similar limits of detection, some preparation procedures do lead to significant variation. We advise that hair should be ground during sample preparation rather than cut.

Alcohol consumption can be assumed if EtG is detectable in hair samples, but the absence of EtG in hair does not necessarily indicate alcohol abstinence. In summary, in both forensic and clinical settings (such as for liver transplant patients, or during the monitoring of alcohol dependent patients), EtG quantification can be a useful tool for the objective detection of alcohol consumption over a much larger time window than the clearance of alcohol from the body. However, care must be taken when interpreting the results.

\section{Role of funding source}

Nothing declared.

\section{Contributors}

C. L. Crunelle prepared the first draft. H. Neels, A. L. N. van Nuijs, W.E. Lambert, P. Michielsen, M. Yegles, A. Covaci, M. De Doncker, K.
Maudens, B. Sabbe and G. Dom actively participated in writing and revising the manuscript for publication.

\section{Conflict of interest}

No conflict declared.

\section{Acknowledgement}

We kindly thank Dr. George Hatfield and Patricia Hatfield for the revisions made in the English language.

\section{References}

Aderjan, R., Besserer, H., Sachs, H., Schmitt, G., Skopp, G., 1994. Ethyl Glucuronide - A Non Volatile Metabolite in Human Hair. In: Proceedings of the TIAFT-SOFT Joint Meeting, Abstract 12, Tampa, FL.

Agius, R., Nadulski, N., Kahl, H.G., Schräder, J., Dufaux, B., Yegles, M., Pragst, F., 2010. Validation of a headspace solid-phase microextraction-GCMS/MS for the determination of ethyl glucuronide in hair according to forensic guidelines. Forensic Sci. Int. 196, 3-9.

Agius, R., Ferreira, L.M., Yegles, M., 2012. Can ethyl glucuronide in hair be determined only in $3 \mathrm{~cm}$ hair strands? Forensic Sci. Int. 218, 3-9.

Albermann, M.E., Musshoff, F., Madea, B., 2010. A fully validated high-performance liquid chromatography-tandem mass spectrometry method for the determination of ethyl glucuronide in hair for the proof of strict alcohol abstinence. Anal. Bioanal. Chem. 396, 2441-2447.

Albermann, M.E., Musshoff, F., Aengenheister, L., Madea, B., 2012a. Investigations on the influence of different grinding procedures on measured ethyl glucuronide concentrations in hair determined with an optimized and validated LC-MS/MS method. Anal. Bioanal. Chem. 403, 769-776.

Albermann, M.E., Musshoff, F., Doberentz, E., Heese, P., Banger, M., Madea, B., 2012b. Preliminary investigations on ethyl glucuronide and ethyl sulfate cutoffs for detecting alcohol consumption on the basis of an ingestion experiment and on data from withdrawal treatment. Int. J. Legal Med. 126, 757-764.

Alt, A., Janda, I., Seidl, S., Wurst, F.M., 2000. Determination of ethyl glucuronide in hair samples. Alcohol Alcohol. 35, 313-314.

Alvarez, I., Bermejo, A.M., Tabernero, M.J., Fernandez, P., Cabarcos, P., Lopez, P., 2009. Microwave-assisted extraction: a simpler and faster method for the determination of ethyl glucuronide in hair by gas chromatography-mass spectrometry. Anal. Bioanal. Chem. 393, 1345-1350.

Anton, R.F., Lieber, C., Tabakoff, B., CDTect Study Group, 2002. Carbohydratedeficient transferrin and gamma-glutamyltransferase for the detection and monitoring of alcohol use: results from a multisite study. Alcohol. Clin. Exp. Res. 26, 1215-1222.

Appenzeller, B.M., Schuman, M., Yegles, M., Wennig, R., 2007a. Ethyl glucuronide concentration in hair is not influenced by pigmentation. Alcohol Alcohol. 42 326-327.

Appenzeller, B.M., Agirman, R., Neuberg, P., Yegles, M., Wennig, R., 2007b. Segmental determination of ethyl glucuronide in hair: a pilot study. Forensic Sci. Int. 173, 87-92.

Aradottir, S., Asanovska, G., Gjerss, S., Hansson, P., Alling, C., 2006. Phosphatidylethanol (PEth) concentrations in blood are correlated to reported alcohol intake in alcohol-dependent patients. Alcohol Alcohol. 41, 431-437.

Arndt, T., Schröfel, S., Stemmerich, K., 2013. Ethyl glucuronide identified in commercial hair tonics. Forensic Sci. Int. 231, 195-198.

Auwärter, V., Sporkert, F., Hartwig, S., Pragst, F., Vater, H., Diefenbacher, A., 2001 Fatty acid ethyl esters in hair as markers of alcohol consumption. Segmental hair analysis of alcoholics, social drinkers, and teetotalers. Clin. Chem. 47, 2114-2123.

Boscolo-Berto, R., Viel, G., Montisci, M., Terranova, C., Favretto, D., Ferrara, S.D., 2013. Ethyl glucuronide concentration in hair for detecting heavy drinking and/or abstinence: a meta-analysis. Int. J. Legal Med. 127, 611-619.

Böttcher, M., Beck, O., Helander, A., 2008. Evaluation of a new immunoassay for urinary ethyl glucuronide testing. Alcohol Alcohol. 43, 46-48.

Cabarcos, P., Hassan, H.M., Tabernero, M.J., Scott, K.S., 2012. Analysis of ethyl glucuronide in hair samples by liquid chromatography-electrospray ionization-tandem mass spectrometry (LC-ESI-MS/MS). J. Appl. Toxicol. 33, 638-643.

Concheiro, M., Cruz, A., Mon, M., de Castro, A., Quintela, O., Lorenzo, A., LopezRivadulla, M., 2009. Ethylglucuronide determination in urine and hair from alcohol withdrawal patients. J. Anal. Toxicol. 33, 155-161.

Conigrave, K.M., Davies, P., Haber, P., Whitfield, J.B., 2003. Traditional markers of excessive alcohol use. Addiction 98, 31-43.

Cooper, G.A., Kronstrand, R., Kintz, P., Society of Hair Testing, 2012. Society of hair testing guidelines for drug testing in hair. Forensic Sci. Int. 218, 20-24.

Dahl, H., Stephanson, N., Beck, O., Helander, A., 2002. Comparison of urinary excretion characteristics of ethanol and ethyl glucuronide. J. Anal. Toxicol. 26, 201-204.

Dettling, A., Skopp, G., Graw, M., Haffner, H.T., 2008. The influence of sex hormones on the elimination kinetics of ethanol. Forensic Sci. Int. 177, 85-89. 
Foti, R.S., Fisher, M.B., 2005. Assessment of UDP-glucuronosyltransferase catalyzed formation of ethyl glucuronide in human liver microsomes and recombinant UGTs. Forensic Sci. Int. 153, 109-116.

Green, S.J., Wilson, J.F., 1996. The effect of hair color on the incorporation of methadone into hair in the rat. J. Anal. Toxicol. 20, 121-123.

Harkey, M.R., 1993. Anatomy and physiology of hair. Forensic Sci. Int. 63, 9-18.

Hietala, J., Puukka, K., Koivisto, H., Anttila, P., Niemelä, O., 2005. Serum gammaglutamyl transferase in alcoholics, moderate drinkers and abstainers: effect on GT reference intervals at population level. Alcohol Alcohol. 40, 511-514.

Høiseth, G., Bernard, J.P., Karinen, R., Johnsen, L., Helander, A., Christophersen, A.S., Mørland, J., 2007. A pharmacokinetic study of ethyl glucuronide in blood and urine: applications to forensic toxicology. Forensic Sci. Int. 172, 119-124.

Høiseth, G., Morini, L., Ganss, R., Nordal, K., Mørland, J., 2013. Higher levels of hair ethyl glucuronide in patients with decreased kidney function. Alcohol. Clin. Exp. Res. 37, 14-16.

Jaakonmaki, P.I., Knox, K.L., Horning, E.C., Horning, M.G., 1967. The characterization by gas-liquid chromatography of ethyl- $\beta$-D-glucosiduronic acid as a metabolite of ethanol in rat and man. Eur. J. Pharmacol. 1, 63-70.

Janda, I., Weinmann, W., Kuehnle, T., Lahode, M., Alt, A., 2002. Determination of ethyl glucuronide in human hair by SPE and LC-MS/MS. Forensic Sci. Int. 128, 59-65.

Jones, A.W., 2010. Evidence-based survey of the elimination rates of ethanol from blood with applications in forensic casework. Forensic Sci. Int. 200, 1-20.

Jurado, C., Soriano, T., Giménez, M.P., Menéndez, M., 2004. Diagnosis of chronic alcohol consumption. Hair analysis for ethyl-glucuronide. Forensic Sci. Int. 145, $161-166$.

Kamil, I.A., Smith, J.N., Williams, R.T., 1952. A new aspect of ethanol metabolism: isolation of ethylglucuronide. Biochem. J. 51, 32-33.

Kerekes, I., Yegles, M., 2013. Coloring, bleaching, and perming: influence on EtG content in hair. Ther. Drug. Monit. 35, 527-529.

Kerekes, I., Yegles, M., Grimm, U., Wennig, R., 2009. Ethyl glucuronide determination: head hair versus non-head hair. Alcohol Alcohol. 44, 62-66.

Kharbouche, H., Sporkert, F., Troxler, S., Augsburger, M., Mangin, P., Staub, C., 2009. Development and validation of a gas chromatography-negative chemical ionization tandem mass spectrometry method for the determination of ethyl glucuronide in hair and its application to forensic toxicology. J. Chromatogr. B: Anal. Technol. Biomed. Life Sci. 877, 2337-2343.

Kharbouche, H., Steiner, N., Morelato, M., Staub, C., Boutrel, B., Mangin, P., Sporkert, F., Augsburger, M., 2010. Influence of ethanol dose and pigmentation on the incorporation of ethyl glucuronide into rat hair. Alcohol 44, 507-514.

Kharbouche, H., Faouzi, M., Sanchez, N., Daeppen, J.B., Augsburger, M., Mangin, P., Staub, C., Sporkert, F., 2012. Diagnostic performance of ethyl glucuronide in hair for the investigation of alcohol drinking behavior: a comparison with traditional biomarkers. Int. J. Legal Med. 126, 243-250.

Kintz, P., 2012. Consensus of the Society of Hair Testing on hair testing for chronic excessive alcohol consumption 2011. Forensic Sci. Int. 2018, 2.

Kintz, P., Villain, M., Vallet, E., Etter, M., Salquebre, G., Cirimele, V., 2008. Ethyl glucuronide: unusual distribution between head hair and pubic hair. Forensic Sci. Int. 176, 87-90.

Kronstrand, R., Brinkhagen, L., Nyström, F.H., 2012. Ethyl glucuronide in human hair after daily consumption of 16 or $32 \mathrm{~g}$ of ethanol for 3 months. Forensic Sci. Int. 215, 51-55

Kwo, P.Y., Ramchandani, V.A., O’Connor, S., Amann, D., Carr, L.G., Sandrasegaran, K., Kopecky, K.K., Li, T.K., 1998. Gender differences in alcohol metabolism: relationship to liver volume and effect of adjusting for body mass. Gastroenterology 115 , 1552-1557

Lamoureux, F., Gaulier, J.M., Sauvage, F.L., Mercerolle, M., Vallejo, C., Lachaître, G., 2009. Determination of ethyl-glucuronide in hair for heavy drinking detection using liquid chromatography-tandem mass spectrometry following solid-phase extraction. Anal. Bioanal. Chem. 394, 1895-1901.

Li, T.K., Beard, J.D., Orr, W.E., Kwo, P.Y., Ramchandani, V.A., Thomasson, H.R., 2000. Variation in ethanol pharmacokinetics and perceived gender and ethnic differences in alcohol elimination. Alcohol. Clin. Exp. Res. 24, 415-416.

Maenhout, T.M., De Buyzere, M.L., Delanghe, J.R., 2013. Non-oxidative ethanol metabolites as a measure of alcohol intake. Clin. Chim. Acta 415, 322-329.

Majhi, S., Baral, N., Lamsal, M., Mehta, K.D., 2006. De Ritis ratio as diagnostic marker of alcoholic liver disease. Nepal Med. Coll. J. 8, 40-42.

Małkowska, A., Szutowski, M., Dyr, W., 2012. Deposition of ethyl glucuronide in WHP rat hair after chronic ethanol intake. Pharmacol. Rep. 64, 586-593.

Martins Ferreira, L., Binz, T., Yegles, M., 2012. The influence of ethanol containing cosmetics on ethyl glucuronide concentration in hair. Forensic Sci. Int. 218, $123-125$.

Mönch, B., Becker, R., Nehls, I., 2013. Quantification of ethyl glucuronide in hair: effect of milling on extraction efficiency. Alcohol Alcohol. 48, 558-563.

Morini, L., Politi, L., Groppi, A., Stramesi, C., Polettini, A., 2006. Determination of ethyl glucuronide in hair samples by liquid chromatography/electrospray tandem mass spectrometry. J. Mass Spectrom. 41, 34-42.

Morini, L., Zucchella, A., Polettini, A., Politi, L., Groppi, A., 2010. Effect of bleaching on ethyl glucuronide in hair: an in vitro experiment. Forensic Sci. Int. 198, 23-27.

Neumark, Y.D., Friedlander, Y., Durst, R., Leitersdorf, E., Jaffe, D., Ramchandani, V.A., O'Connor, S., Carr, L.G., Li, T.K., 2004. Alcohol dehydrogenase polymorphisms influence alcohol-elimination rates in a male Jewish population. Alcohol. Clin. Exp. Res. 28, 10-14.

Niemelä, O., 2007. Biomarkers in alcoholism. Clin. Chim. Acta 377, 39-49.
Paul, R., Tsanaclis, L., Kingston, R., Berry, A., Guwy, A., 2011. Simultaneous determination of GHB and EtG in hair using GCMS/MS. Drug Test. Anal. 3, 201-205.

Pianta, A., Liniger, B., Baumgartner, M.R., 2013. Ethyl glucuronide in scalp and nonhead hair: an intra-individual comparison. Alcohol Alcohol. 48, 295-302.

Pirro, V., Di Corcia, D., Pellegrino, S., Vincenti, M., Sciutteri, B., Salomone, A., 2011. A study of distribution of ethyl glucuronide in different keratin matrices. Forensic Sci. Int. 210, 271-277.

Politi, L., Morini, L., Leone, F., Polettini, A., 2006. Ethyl glucuronide in hair: is it a reliable marker of chronic high levels of alcohol consumption? Addiction 101, 1408-1412.

Pragst, F., Balikova, M.A., 2006. State of the art in hair analysis for detection of drug and alcohol abuse. Clin. Chim. Acta 370, 17-49.

Pragst, F., Yegles, M., 2008. Determination of fatty acid ethyl esters (FAEE) and ethyl glucuronide (EtG) in hair: a promising way for retrospective detection of alcohol abuse during pregnancy? Ther. Drug Monit. 30, 255-263.

Rachamin, G., MacDonald, J.A., Wahid, S., Clapp, J.J., Khanna, J.M., Israel, Y., 1980. Modulation of alcohol dehydrogenase and ethanol metabolism by sex hormones in the spontaneously hypertensive rat. Effect of chronic ethanol administration. Biochem. J. 186, 483-490.

Rainio, J., Kultti, J., Kangastupa, P., Tuomi, H., Ahola, S., Karhunen, P.J., Helander, A. Niemelä, O., 2013. Immunoassay for ethyl glucuronide in vitreous humor: a new tool for postmortem diagnostics of alcohol use. Forensic Sci. Int. 226, 261-265.

Rehm, J., Gmel, G., Sempos, C.T., Trevisan, M., 2003. Alcohol-related morbidity and mortality. Alcohol Res. Health 27, 39-51.

Reid, R.W., O'Connor, F.L., Deakin, A.G., Ivery, D.M., Crayton, J.W., 1996. Cocaine and metabolites in human graying hair: pigmentary relationship. J. Toxicol. Clin. Toxicol. 34, 685-690.

Rinck, D., Frieling, H., Freitag, A., Hillemacher, T., Bayerlein, K., Kornhuber, J., Bleich, S., 2007. Combinations of carbohydrate-deficient transferrin, mean corpuscular erythrocyte volume, gamma-glutamyltransferase, homocysteine and folate increase the significance of biological markers in alcohol dependent patients. Drug Alcohol Depend. 89, 55-60.

Sarkola, T., Dahl, H., Eriksson, C.J., Helander, A., 2003. Urinary ethyl glucuronide and 5-hydroxytryptophol levels during repeated ethanol ingestion in healthy human subjects. Alcohol Alcohol. 38, 347-351.

Schubert, W., Mattern, R., 2009. The German Driving License Regranting Guidelines. Kirschbaum Verlag Bonn, pp. 178.

Seitz, H.K., Xu, Y., Simanowski, U.A., Osswald, B., 1992. Effect of age and gender on in vivo ethanol elimination, hepatic alcohol dehydrogenase activity, and NAD+ availability in F344 rats. Res. Exp. Med. (Berl.) 192, 205-212.

Shankar, K., Ronis, M.J., Badger, T.M., 2007. Effects of pregnancy and nutritional status on alcohol metabolism. Alcohol Res. Health 30, 55-59.

Sharpe, P.C., 2001. Biochemical detection and monitoring of alcohol abuse and abstinence. Ann. Clin. Biochem. 38, 652-664.

Shi, Y., Shen, B., Xiang, P., Yan, Y., Shen, M., 2010. Determination of ethyl glucuronide in hair samples of Chinese people by protein precipitation (PPT) and large volume injection-gas chromatography-tandem mass spectrometry (LVI-GC/MS/MS). J. Chromatogr. B: Analyt. Technol. Biomed. Life Sci. 878 3161-3166.

Skopp, G., Schmitt, G., Pötsch, L., Drönner, P., Aderjan, R., Mattern, R., 2000. Ethy glucuronide in human hair. Alcohol Alcohol. 35, 283-285.

Sobell, L.C., Agrawal, S., Sobell, M.B., 1997. Factors affecting agreement between alcohol abusers' and their collaterals' reports. J. Stud. Alcohol 58, 405-413.

SoHT, 2013. Official website of the Society of Hair Testing, URL: http://www.soht.org (accessed 20.08.13).

Sporkert, F., Kharbouche, H., Augsburger, M.P., Klemm, C., Baumgartner, M.R., 2012 Positive EtG findings in hair as a result of a cosmetic treatment. Forensic Sci. Int. 218, 97-100.

Stewart, S.H., Koch, D.G., Willner, I.R., Randall, P.K., Reuben, A., 2013. Hair ethy glucuronide is highly sensitive and specific for detecting moderate-to-heavy drinking in patients with liver disease. Alcohol Alcohol. 48, 83-87.

Suesse, S., Pragst, F., Mieczkowski, T., Selavka, C.M., Elian, A., Sachs, H., Hastedt, M., Rothe, M., Campbell, J., 2012. Practical experiences in application of hair fatty acid ethyl esters and ethyl glucuronide for detection of chronic alcohol abuse in forensic cases. Forensic Sci. Int. 218, 82-89.

Süsse, S., Selavka, C.M., Mieczkowski, T., Pragst, F., 2010. Fatty acid ethyl ester concentrations in hair and self-reported alcohol consumption in 644 cases from different origin. Forensic Sci. Int. 196, 111-117.

Tarcomnicu, I., van Nuijs, A.L.N., Aerts, K., De Doncker, M., Covaci, A., Neels, H., 2010 Ethyl glucuronide determination in meconium and hair by hydrophilic interaction liquid chromatography-tandem mass spectrometry. Forensic Sci. Int. 196, $121-127$.

Toneatto, T., Sobell, L.C., Sobell, M.B., 1992. Predictors of alcohol abusers' inconsis tent self-reports of their drinking and life events. Alcohol. Clin. Exp. Res. 16 542-546.

Tønnesen, H., Hejberg, L., Frobenius, S., Andersen, J.R., 1986. Erythrocyte mean cel volume - correlation to drinking pattern in heavy alcoholics. Acta Med. Scand. 219, 515-518.

van Pelt, J., 1997. Carbohydrate-deficient transferrin: a new biochemical marker for chronic excessive alcohol consumption. Ned Tijdschr Geneeskd 141, 773-777.

World Health Organization (WHO), 2001. International Classification of Functioning, Disability and Health. WHO, Geneva.

Wurst, F.M., Skipper, G.E., Weinmann, W., 2003. Ethyl glucuronide - the direct ethanol metabolite on the threshold from science to routine use. Addiction 98 (S2), 51-61. 
Wurst, F.M., Alexson, S., Wolfersdorf, M., Bechtel, G., Forster, S., Alling, C., Aradóttir, S., Jachau, K., Huber, P., Allen, J.P., Auwärter, V., Pragst, F., 2004. Concentration of fatty acid ethyl esters in hair of alcoholics: comparison to other biological state markers and self-reported ethanol intake. Alcohol Alcohol. 39, 33-38.

Wurst, F.M., Yegles, M., Alling, C., Aradottir, S., Dierkes, J., Wiesbeck, G.A., Halter, C.C., Pragst, F., Auwaerter, V., 2008. Measurement of direct ethanol metabolites in a case of a former driving under the influence (DUI) of alcohol offender, now claiming abstinence. Int. J. Legal Med. 122, 235-239.

Yegles, M., Labarthe, A., Auwärter, V., Hartwig, S., Vater, H., Wennig, R., Pragst, F.,

2004. Comparison of ethyl glucuronide and fatty acid ethyl ester concentrations in hair of alcoholics, social drinkers and teetotallers. Forensic Sci. Int. 145, 167-173. 